\title{
Improvement of Voltage Profile and Reduce Power System Losses by using Multi Type Facts Devices
}

\author{
Ch.Rambabu \\ Department of EEE \\ Sri Vasavi Engg. College \\ Tadepalligudem, W.G.Dt, \\ A.P, India - 534101
}

\author{
Dr.Y.P.Obulesu \\ Department of EEE \\ L.B.R.College of Engineering \\ Mylavaram, Krishna Dist \\ A.P, India - 521230
}

\author{
Dr.Ch.Saibabu \\ Department of EEE \\ JNTUCollege of Engineering \\ Kakinada, E.G.Dt \\ A.P, India - 533003
}

\begin{abstract}
In emerging electric power systems, increased transactions often lead to the situations where the system no longer remains in secure operating region. The flexible Ac transmission system (FACTS) controllers can play an important role in the power system security enhancement. However, due to high capital investment, it is necessary to locate these controllers optimally in the power system. FACTS devices can regulate the active and reactive power control as well as adaptive to voltage-magnitude control simultaneously because of their flexibility and fast control characteristics. Placement of these devices in suitable location can lead to control in line flow and maintain bus voltages in desired level and so improve voltage stability margins.

This paper proposes a systematic method by which optimal location of MUTI TYPE FACTS DEVICES to be installed. FACTS DEVICES model is incorporated into a NewtonRaphson algorithm to perform load flow analysis. Optimizing its location becomes a concern when coming to the practical implementation stage. Proposed algorithm is tested on IEEE 5 bus power system for optimal allocation of multi-type FACTS devices and results are presented.
\end{abstract}

\section{Keywords}

Voltage Stability, FACTS Devices, Optimal Allocation.

\section{INTRODUCTION}

Modern power systems are prone to widespread failures. With the increase in power demand, operation and planning of large interconnected power system are becoming more and more complex, so power system will become less secure. Operating environment, conventional planning and operating methods can leave power system exposed to instabilities. Voltage instability is one of the phenomena which have result in a major blackout. Moreover, with the fast development of restructuring, the problem of voltage stability has become a major concern in deregulated power systems. To maintain security of such systems, it is desirable to plan suitable measures to improve power system security and increase voltage stability margins. FACTS devices can regulate the active and reactive power control as well as adaptive to voltage-magnitude control simultaneously because of their flexibility and fast control characteristics. Placement of these devices in suitable location can lead to control in line flow and maintain bus voltages in desired level and so improve voltage stability margins.

FACTS devices can regulate the active and reactivepower control as well as adaptive to voltage magnitude control simultaneously by their fast control characteristics and their continuous compensating capability and so reduce flow of heavily loaded lines and maintain voltages in desired level.[1]

Besides, FACTS devices can improve both transient and small signal stability margins. Controlling the power flows in the network, under normal and abnormal conditions of the network, can help to reduce flows in heavily loaded lines, reduce system power loss, and so improve the stability and performance of the system without generation rescheduling or topological changes in the network [1]. Because of the considerable costs of the FACTS devices, it is so mementos to find out the optimal location for placement of these devices to improve voltage stability margins and enhance network security [2-7].

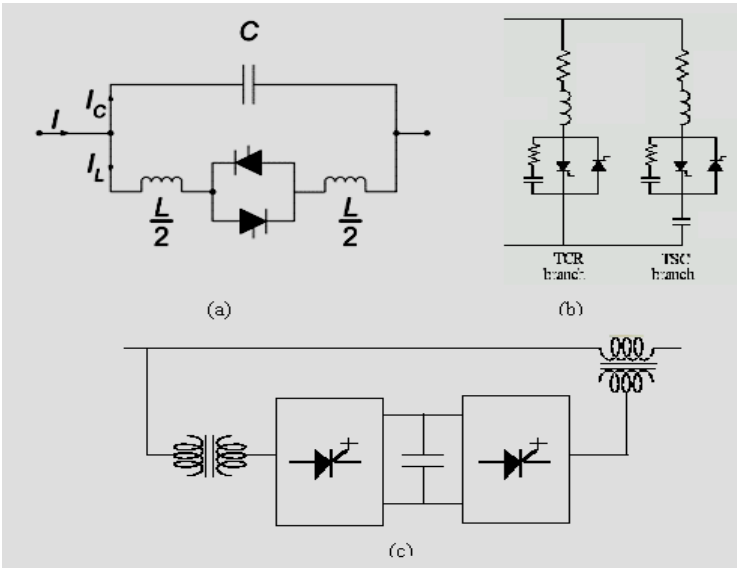

Fig 1. Considered FACTS Devices (a) TCSC (b) SVC (c) UPFC

Effect of FACTS devices on power system security, reliability and loadability has been studied according to proper control objectives [5-15]. Some of papers have been tried to find suitable location for FACTS devices to improve power system security and loadability [14-17]. Optimal allocation of these devices in deregulated power systems has been presented in [18-19].

\section{FACTS DEVICES MODEL}

\subsection{FACTS Devices}

In this paper, three different FACTS devices have been selected to place in suitable location to improve voltage stability margins in power system. These are TCSC, SVC and UPFC. These are shown in Fig 1.

TCSC can change line reactance and SVC can be used to control reactive power in network. UPFC is the most versatile member of FACTS devices family and can be applied in order to control all power flow parameters (i.e. line impedance, bus voltage, and phase angle). Power flow can be controlled and optimized by changing power system parameters using FACTS devices. So optimal choice and allocation of FACTS devices can result in suitable utilization in power system. 


\subsection{Mathematical model of FACTS Devices}

In this paper steady state model of FACTS devices are developed for power flow studies. So TCSC is modeled simply to just modify the reactance of transmission line. SVC and UPFC are modeled using the power injection models [2024]. Models integrated into transmission line for TCSC and UPFC and SVC is modeled is incorporated into the bus as shunt element of transmission line. Mathe-matical models for FACTS devices are implemented by MATLAB programming language.

i TCSC:- Thyristor Controlled Series Capacitor (TCSC) is a series FACTS device which allows rapid and continuous changes of the transmission line impedance. It has great application potential in accurately regulating the power flow on a transmission line, damping inter-area power oscillations, mitigating sub synchronous resonance (SSR) and improving transient stability. The characteristics of a TCSC at steadystate and very low frequencies can be studied using fundamental frequency analytical models .

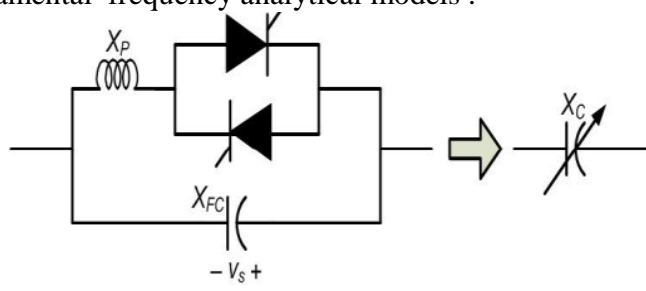

Fig 2. Model of TCSC

In this paper TCSC is modeled by changing transmission line reactance as below:

$$
\begin{aligned}
& X_{i j}=X_{\text {line }}+X_{T C S C}---(1) \\
& X_{T C S C}=r_{T C S C} \cdot X_{\text {line }}----(2)
\end{aligned}
$$

Where $\mathrm{X}_{\text {line }}$ is reactance of transmission line and is compensation factor of TCSC. Rating of TCSC is depended on transmission line where it is located. To prevent overcompensation, TCSC reactance is chosen between -0.7 $\mathrm{X}_{\text {line }}$ to $0.2 \mathrm{X}_{\text {line }}[18]$

ii. SVC :- Static var systems are applied by utilities in transmission applications for several purposes. The primary purpose is usually rapid control of voltage at weak points in a network. Installations may be the midpoint of transmission interconnections or in load areas. In this paper, SVCis assumed to be located at load side.

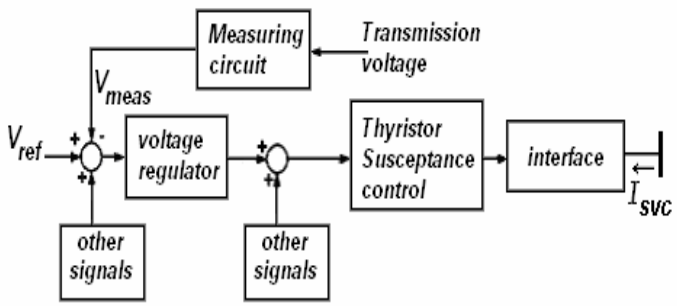

Fig 3: Basic Model of SVC

SVC can be used for both inductive and capacitive compensation. In this paper SVC is modeled as an ideal reactive power injection at bus $\mathrm{i}$ :

$$
\Delta Q_{i}=Q_{S V C}----(3)
$$

iii. UPFC:- The unified power flow controller (UPFC) is the most versatile among a variety FACTS devices which can be used for power flow control, enhancement of transient stability, damping system oscillations and voltage regulations. Load flow control with unified power flow controller can maintain the reliable system operation in the event of additionally demanded power transients. UPFC has been proved to be an effective means for regulating voltage profile and power flow in modern power systems. It facilitates greater control of power, such that it flows on the prescribed transmission routes and secure loading of transmission lines to levels nearer to their thermal limits is possible. In power systems, FACTS DEVICES are used for the best utilization of the existing transmission lines. UPFC is located in order to maximize the system load ability while observing thermal and voltage constraints. Power transmitted by the network to the consumers is increased keeping the power system in a secure state in terms of branch loading and voltage levels.

Two types of UPFC models are reported in papers [22-25]. One is coupled model [22] and other is decoupled model [23-25]. In the first type, UPFC is modeled with series combination of a voltage source and impedance in the transmission line. In decoupled model, UPFC is modeled with two separated buses. First model is more complex compared with the second one because modification of Jacobian matrix in coupled model is inevitable.

While decoupled model can be easily implemented in conventional power flow algorithms without modification of Jacobian matrix elements, in this paper, decoupled model used for modeling UPFC in power flow study (Fig 4)

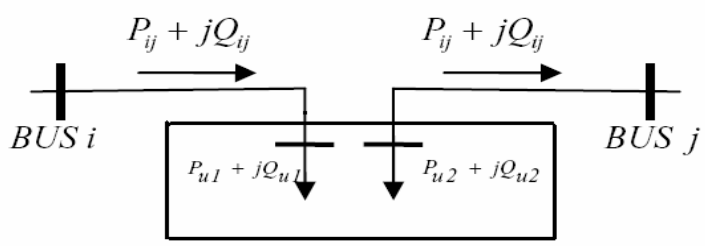

Figure 4. Decoupled model for UPFC

UPFC controls power flow of the transmission line where is installed. To obtain UPFC model in load flow study, it is represented by four variables: $\mathrm{P}_{\mathrm{u} 1}, \mathrm{Q}_{\mathrm{u} 1}, \mathrm{P}_{\mathrm{u} 2}, \mathrm{Q}_{\mathrm{u} 2}$. Assuming UPFC to be lossless, real power flow from bus $i$ to bus $j$ can be expressed as:

$$
P_{i j}=P_{u 1}----(4)
$$

Although UPFC can control the power flow, but cannot generate the real power. So:

$$
P_{u 1}+P_{u 2}=0----(5)
$$

Each reactive power output of UPFC $\mathrm{Q}_{\mathrm{u} 1}, \mathrm{Q}_{\mathrm{u} 2}$ can be set to an arbitrary value depend on rating of UPFC to maintain bus voltage.

\section{SIMULATION RESULTS}

\subsection{Introduction}

Simulation studies were done for different scenarios in IEEE 5 bus power system. Five different scenarios are considered: 
Scenario 1: power System normal operation (without FACTS devices installation).

Scenario 2: one TCSC is installed

Scenario 3: one SVC is installed

Scenario 4: one UPFC is installed

Scenario 5: Multi-type (TCSC, SVC and UPFC)FACTS devices are installed.

The first scenario is normal operation of network without installing any device. In second, third and fourth scenario just installation of one device is considered. Multitype FACTS devices installation is considered in 5th scenario. In this case three different kinds of FACTS devices (shunt, series and combinational compensation device) are used to place in optimal location to improve the voltage profile and reduce the losses of power system.

\subsection{Simulation without FACTS Devices}

\section{Table 1: Power Flow Solution by Newton-Raphson Method}

\begin{tabular}{|c|c|c|c|c|c|c|}
\hline \multirow{2}{*}{$\begin{array}{l}\text { BUS } \\
\text { NO }\end{array}$} & \multirow{2}{*}{$\begin{array}{l}\text { VOLTAGE } \\
\text { MAGNITU }\end{array}$} & \multirow{2}{*}{$\begin{array}{l}\text { VOLTAGE } \\
\text { ANGLE }\end{array}$} & & \multicolumn{4}{|c|}{ LOAD GENERATION } \\
\cline { 4 - 7 } & & & MW & $\begin{array}{l}\text { MVA } \\
\text { RE }\end{array}$ & $\begin{array}{l}\text { MW } \\
\text { PU }\end{array}$ & $\begin{array}{l}\text { MVA } \\
\mathbf{R} \\
\text { PU }\end{array}$ \\
\hline 1 & 1.06000 & 0.00000 & 0.00 & 0.00 & 129.5 & 7.421 \\
\hline 2 & 1.04744 & -2.80635 & 20.0 & 10.00 & 40.00 & 30.00 \\
\hline 3 & 1.02418 & -4.09969 & 45.0 & 15.00 & 0.00 & 0.00 \\
\hline 4 & 1.02357 & -5.32914 & 40.0 & 5.00 & 0.00 & 0.00 \\
\hline 5 & 1.01794 & -6.15026 & 60.0 & 10.00 & 0.00 & 0.00 \\
\hline TOT & & & 165.0 & 40.00 & 169.5 & 22.57 \\
\hline
\end{tabular}

Table 2 : Line losses without FACTS devices

\begin{tabular}{|c|c|c|c|}
\hline \multirow{2}{*}{ BUSNO FROM: } & \multirow{2}{*}{ TO } & \multicolumn{2}{|c|}{ LINE LOSSES } \\
\cline { 3 - 4 } & & MW & MVAR \\
\hline 1 & 2 & 1.41045 & -2.43083 \\
\hline 1 & 3 & 1.19196 & -1.85547 \\
\hline 2 & 3 & 0.35152 & -3.23757 \\
\hline 2 & 4 & 0.44134 & -2.96560 \\
\hline 2 & 5 & 1.12525 & 0.17577 \\
\hline 3 & 4 & 0.03560 & -1.981 \\
\hline 4 & 5 & 0.03071 & -5.11758 \\
\hline TOTAL & & 4.58683 & -17.42109 \\
\hline
\end{tabular}

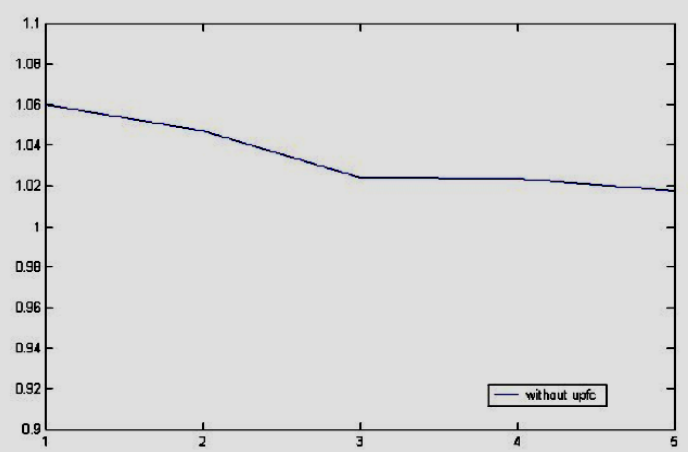

Fig 5: Voltage profile of the test system without FACTS devices.

\subsection{Simulation with TCSC}

Table 3 : Line losses with TCSC

\begin{tabular}{|c|c|c|c|}
\hline BUS From & BUS To & $\begin{array}{c}\text { REAL } \\
\text { POWER LOSS }\end{array}$ & $\begin{array}{c}\text { REACTIVE } \\
\text { POWER LOSS }\end{array}$ \\
\hline 2 & 3 & 6.47328 & -11.66943 \\
\hline 2 & 4 & 6.53247 & -12.03645 \\
\hline 2 & 5 & 6.32411 & -23.88476 \\
\hline 3 & 2 & 6.47642 & -11.66949 \\
\hline 3 & 4 & 6.12821 & -10.85432 \\
\hline 4 & 2 & 6.53872 & -12.03452 \\
\hline 4 & 3 & 6.12834 & -10.85342 \\
\hline 4 & 5 & 6.15325 & -10.87238 \\
\hline 5 & 2 & 6.32984 & -13.85347 \\
\hline 5 & 4 & 6.15096 & -10.87543 \\
\hline
\end{tabular}

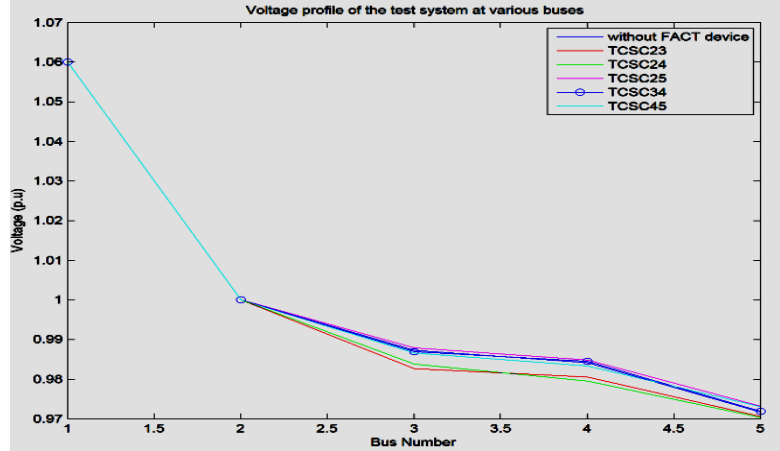

Fig 6: voltage profile of system with TCSC

Here we can observe that by placing TCSC can improve the voltage profile and losses are reduced. The best location for TCSC is between bus 2 and bus 5 to minimize the losses.

\subsection{Simulation with SVC}

Table 4 : Line losses with SVC

\begin{tabular}{|c|c|c|c|}
\hline BUS From & BUS To & $\begin{array}{l}\text { REAL POWER } \\
\text { LOSS }\end{array}$ & $\begin{array}{l}\text { REACTIVE } \\
\text { POWER LOSS }\end{array}$ \\
\hline 2 & 3 & 6.6734 & -9.5535 \\
\hline 2 & 4 & 6.8625 & -8.9328 \\
\hline 2 & 5 & 11.3428 & 5.5864 \\
\hline 3 & 2 & 6.7284 & -9.6334 \\
\hline 3 & 4 & 6.3158 & -10.3962 \\
\hline 4 & 2 & 6.9372 & -8.9694 \\
\hline 4 & 3 & 6.4121 & -10.4043 \\
\hline 4 & 5 & 6.1319 & -11.1986 \\
\hline 5 & 2 & 11.294 & 4.7654 \\
\hline 5 & 4 & 6.1243 & -11.2188 \\
\hline
\end{tabular}

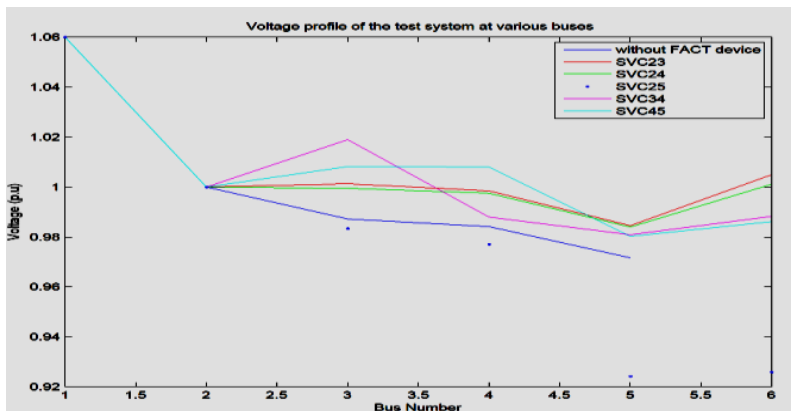

Fig 7: voltage profile of system with SVC

SVC is placed at different locations and observed that voltage profile is improved and losses are reduced. The best location for SVC is between bus 2 and bus 3 to minimize the losses.

\subsection{Simulation with UPFC}

Table 5 : Line losses with UPFC

\begin{tabular}{|c|c|c|c|}
\hline BUS From & BUS To & $\begin{array}{c}\text { REAL } \\
\text { POWER LOSS }\end{array}$ & $\begin{array}{c}\text { REACTIVE } \\
\text { POWER LOSS }\end{array}$ \\
\hline 2 & 3 & 4.79012 & -16.85673 \\
\hline 2 & 4 & 4.70994 & -17.10167 \\
\hline 2 & 5 & 5.02372 & -15.57745 \\
\hline 3 & 2 & 2.92128 & -23.45038 \\
\hline 3 & 4 & 5.04984 & -16.31023 \\
\hline 4 & 2 & 2.91293 & -23.44640 \\
\hline 4 & 3 & 2.91293 & -23.44640 \\
\hline 4 & 5 & 6.22885 & -12.66832 \\
\hline 5 & 2 & 1.37279 & -28.66214 \\
\hline 5 & 4 & 1.37279 & -28.66214 \\
\hline
\end{tabular}




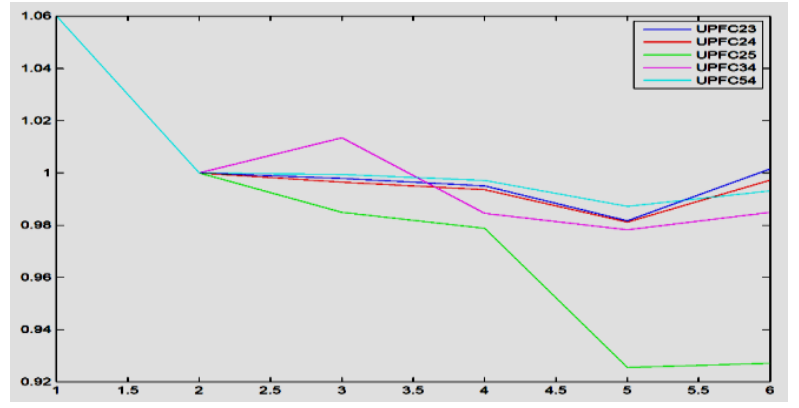

Fig 8: voltage profile of the system with UPFC

UPFC is placed at different locations and observed that voltage profile is improved and losses are reduced. The optimal location for UPFC is between bus 5 and bus 4 to minimize the losses.

\subsection{Simulation with Multi type FACTS}

Total Power Loss in the best voltage profile Scenario of each Configuration:

Table 6 : Line losses with Multi-type FACTS Devices

\begin{tabular}{|c|c|c|}
\hline System & $\begin{array}{c}\text { Total Active } \\
\text { Power loss } \\
\text { (MW) }\end{array}$ & $\begin{array}{c}\text { Total Reactive Power } \\
\text { loss } \\
\text { (MVAR) }\end{array}$ \\
\hline $\begin{array}{c}\text { Without FACT } \\
\text { Device }\end{array}$ & 6.122 & -10.773 \\
\hline UPFC-5--4 & 2.858 & -20.944 \\
\hline TCSC-2--5 & 6.329 & -13.884 \\
\hline SVC-2-3 & 6.673 & -9.558 \\
\hline $\begin{array}{c}\text { Multi-type FACT } \\
\text { Devices }\end{array}$ & 3.162 & -20.837 \\
\hline
\end{tabular}

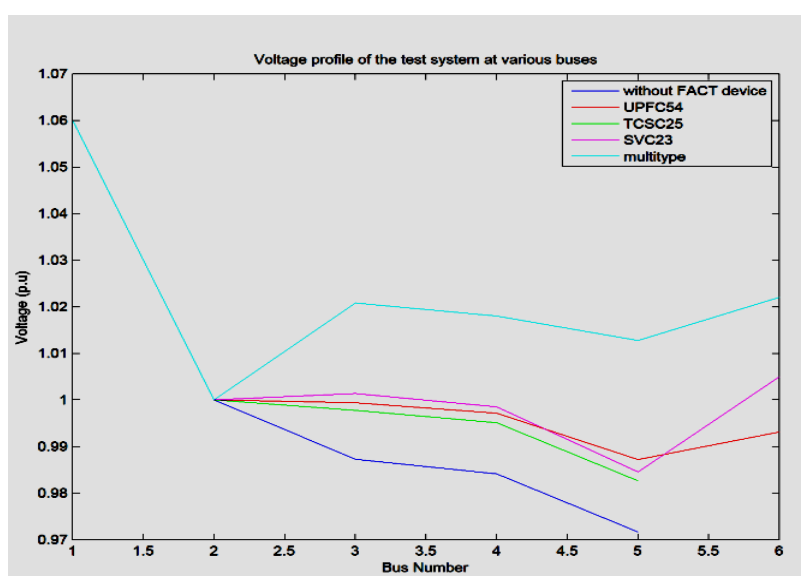

Fig 9: voltage profile of system with multi-type FACTS devices.

So multi-type FACTS devices should be placed in optimal location to improve voltage profile and reduce losses in the network. Table 6 shows optimal location of devices in scenarios. Voltage profiles are shown for different scenarios in Fig. 9.

This indicates that the best voltage profile is achieved by multi-type installation of multi type FACTS devices. But economic aspects must be considered.

\section{CONCLUSION}

This paper gives a concise idea on each of the FACT devices, UPFC, TCSC and SVC. Their individual contribution towards the improvement of voltage profile and reduction of power losses has been tested on a 5-bus system. The combination of all the three FACTS devices has been considered, as a multi type FACTS devices effect on the maintenance of the voltage profile and reduction of power loss. The performance of UPFC on the system, when located optimally is considered to be best comparatively with respect to each of the three devices. The multi-type FACTS devices located at their own optimal locations is observed to have a better voltage profile and power loss.

\section{REFERENCES}

1. F.D. Galiana, K. Almeida, M. Toussaint, J. Griffin, and D. Atanackovic: "Assessment and Control of the Impact of FACTS Devices on Power System Performance", IEEE Trans. Power Systems, Vol. 11, No. 4, Nov 1996

2. N.G. Hingurani, L. Gyugyi, Understanding FACTS: Concepts and Technology of Flexible AC Transmission Systems, IEEE Press, New York, 2000.

3. M. Noroozian, L. Angquist, M. Ghandhari, G. Anderson, "Improv-ing Power System Dynamics by Seriesconnected FACTS De-vices," IEEE Trans. on Power Delivery, Vol. 12, No.4, October 1997.

4. M. Noroozian, L. Angquist, M. Ghandhari, "Use of UPFC for Optimal Power Flow Control," IEEE Trans. on Power Delivery, Vo1.12, No.4, October 1997.

5. R. Billinton, M. Fotuhi-Firuzabad, O.S. Faried, S. Aboreshaid, "Impact of Unified Power Flow Controllers on Power System Reliability," IEEE Trans. on Power Systems, Vo1.15, No.1, February 2000.

6. J.A. Momoh, J. Zhu, G.D. Boswell, S. Hoffman, "Power System Security Enhancement by OPF with Phase Shifter," IEEE Trans. on Power Systems, Vol. 16, No.2, May 2001.

7. S. Sung-Hwan, L. Jung-Uk, M. Seung-Il, "FACTS Operation Scheme for Enhancement of Power System Security," in Proc of IEEE Power Tech Conference, Bologna, 2003, Vol. 3, pp. 36-41.

8. K. Sun-Ho, L. Jung-Uk, M. Seung-Il, "Enhancement of Power System Security Level Through the Power Flow Control of UPFC," in Proc. of the IEEE Power Engineering Society Summer Meeting, 2000, Vol. 1, pp. $38-43$.

9. A. Kazemi, H.A. Shayanfar, A. Rabiee, J. Aghaie, "Power System Security Improvement using the Unified Power Flow Controller," in Proc.of the IEEE Power India Conference, 2006, pp. 1-5.

10. J.G. Singh, S.N. Singh, S.C. Srivastava, "Placement of FACTS Controllers for Enhancing Power System Loadability," in Proc.of the IEEE Power India Conference, 2006, pp. 10-17.

11. F. Jurado, J.A. Rodriguez, "Optimal Location of SVC based on System Loadability and Contingency Analysis", in Proc. of the Emerging Technologies and Factory Automation Conference, 1999, Vol. 2, pp. 1193-1199.

12. S.N. Sing, A.K. David, "A New Approach for Placement of FACTS Devices in Open Power Markets," IEEE Power Engineering Review, 2001, Vol. 21, No.9, pp. 58-60.

13. D. Thukaram, L. Jenkins, K. Visakha, "Improvement of system security with unified-power-flow controller at suitable locations under network contingencies of interconnected systems", IEEE Trans. on Generation, Transmission and Distribution, Vol. 152, Issue 5, 9 Sept. 2005, pp. $682-690$. 
14. K.S. Verma, S.N. Singh, and H.O. Gupta, "Location of Unified Power Flow Controller for Congestion Management", Electric Power System Research, Vol. 58, pp 89-96,2001

15. S. Gerbex, R. Chekaoui, A.J. Germond, "Optimal Location of Multi-type FACTS Devices in a Power System by Means of Genetic Algorithm", IEEE Trans. on Power Systems, Vol. 16, August 2001, pp. 537-544.

16. S. Gerbex, R. Cherkaoui, A.J. Germond, "Optimal Location of FACTS Devices to Enhance Power System Security", in Proc. of the IEEE Power Tech Conference, 2003, Bologna, Vol. 3, pp. 1-7.

17. L.J. Cai and L. Erlich, "Optimal Choice and Allocation of FACTS Devices in Deregulated Electricity Market using Genetic Algorithms", in Proc. of the IEEE Power Systems Conference and Exposition, 2004, vol. 1, pp. $201-207$.

18. J. Baskaran, V. Palanisamy, "Genetic Algorithm Applied to Optimal Location of FACTS Device in a Power System Network considering economic saving cost", Academic Open Internet Journal, 2005, Vol. 15, pp. 1-7.

19. D. Thukaram, L. Jenkins, K. Visakha, "Improvement of System Security with Unified Power Flow Controller at Suitable Locations under Network Contingencies of Interconnected Systems," in IEEE Trans. on Generation, Transmission and Distribution, 2005, Vol. 152, Issue 5, pp. $682-690$.

20. K.S. Verma, S.N. Singh, and H.O. Gupda, "Location of Unified Power Flow Controller for Congestion Management", Electric power system research, 2001, Vol. 58, pp. 89-96.

21. M. Noroozian, L. Angquist, M. Ghandhari, G. Andersson, "Use of UPFC for Optimal Power Flow Control", IEEE Trans. on Power Delivery, 1997, Vol. 12, No. 4, pp. 16291634.

22. S.H. Kim, J.U. Lim, S.II. Moon, "Enhancement of Power System Security Level through the Power Control of UPFC", IEEE, 2000, pp. 38-43.

23. T.H. Kim, J.Ch. Seo, J.U. Lim, S. Moon, J.K. Park, B.M. Han, "A Decoupled unified power flow controller model for power flow considering limit resolution", IEEE, 1998, pp. 1190-1195.
24. J.U. Lim, S.I. Moon, "An operation scheme of UPFC's considering operation objective and states", in Proc. of the IEEE Power Tech Conference, Bologna, 2003, pp. 610615

25. P. Kessel, H. Glavitsch, "Estimating the Voltage Stability and Loadability of Power Systems", IEEE Trans. on Power Delivery, 1986, Vol. 1, pp. 1586-1599.

\section{AUTHOR PROFILES}

Ch.Rambabu received the Bachelor of Engineering degree in electrical \& electronics engineering from Madras University, in 2000 and Master's degree from JNTU Anantapur in 2005. $\mathrm{He}$ is a research student of JNTU Kakinada. Currently, he is an Associate Professor at Sri Vasavi Engineerung College. His interests are in power system control and FACTS.

Dr. Y.P.Obulesu received his B.E degree in Electrical Engineering from Andhra University, Visakhapatnam in 1996. M.Tech degree from IIT, Kharagpur, in 1998.He received his $\mathrm{PhD}$ degree from Jawaharlal Nehru Technological University, Hyderabad, in 2006. Currently he is working as a Professor and head of Dept. of EEE at LBRCEC, Mylavaram. He has published several National and International Journals and Conferences. His area of interest is the simulation and design of power electronics systems, DSP controllers, fuzzy logic and neural network application to power electronics and drives.

Dr. Ch. Sai Babu received the B.E from Andhra University (Electrical \& Electronics Engineering), M.Tech in Electrical Machines and Industrial Drives from REC, Warangal and $\mathrm{PhD}$ in Reliability Studies of HVDC Converters from JNTU, Hyderabad. Currently he is working as a Professor in Dept. of EEE in JNTUCEK, Kakinada. He has published several National and International Journals and Conferences. His area of interest is Power Electronics and Drives, Power System Reliability, HVDC Converter Reliability, Optimization of Electrical Systems and Real Time Energy Management. 